\title{
A Rare Presentation of Intraperitoneal Ectopic Varices Rupture
}

\author{
Ryuta Shigefuku, Motoh Iwasa, Kyoko Yoshikawa and Yoshiyuki Takei
}

Key words: intraperitoneal ectopic varices rupture, liver cirrhosis, portal hypertension

(Intern Med 60: 959-960, 2021)

(DOI: 10.2169/internalmedicine.6012-20)

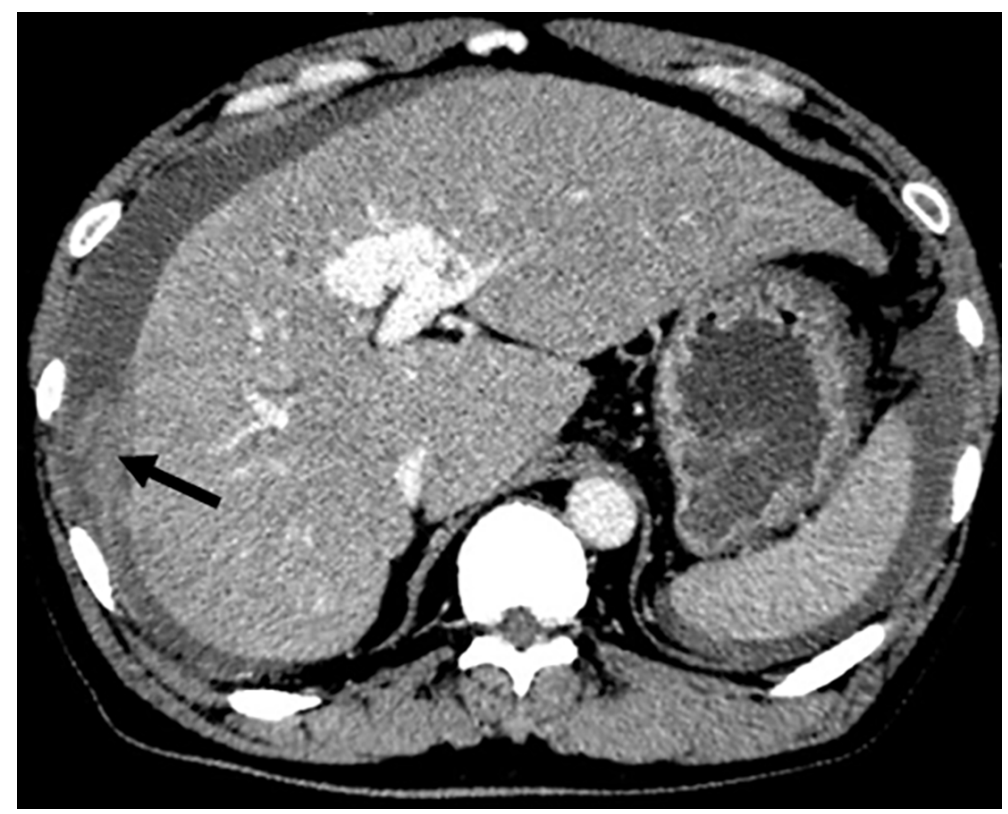

Picture 1.

A 57-year-old man was transferred due to abdominal pain. He was a heavy drinker (ethanol $190 \mathrm{~g} /$ day) and presented with Child-Pugh class-B. Computed tomography (CT) showed cirrhosis, esophageal varices, fluid collection with hematoma (Picture 1, arrow), and enlarged collateral veins with saccular dilatation from the umbilical portion of the portal vein to the right femoral vein. We presumed he had bleeding from acquired portosystemic collaterals with cirrhosis. His vital signs were stable, and careful monitoring of intraperitoneal fluid volume was deemed prudent. Three days after admission, he developed shock and was subsequently reimaged with $\mathrm{CT}$. Based on the findings, he was diagnosed with increasing hematoma (Picture 2A, B, arrows) and intraperitoneal re-hemorrhaging from ectopic varices
(Picture 2B, C, arrowheads). We attempted to achieve hemostasis using balloon-occluded retrograde transvenous obliteration, but he had progressive hemodynamic instability, so we had to stop the procedure before the culprit vessel could be detected. He ultimately died from intraperitoneal bleeding. Intraperitoneal ectopic varices rupture is a rare and lethal complication brought on by portal hypertension. If a diagnosis of impending rupture is made, immediate interventional radiological or surgical treatment should be performed $(1,2)$.

The authors state that they have no Conflict of Interest (COI).

Department of Gastroenterology and Hepatology, Mie University Graduate School of Medicine, Japan

Received: August 2, 2020; Accepted: August 27, 2020; Advance Publication by J-STAGE: October 14, 2020

Correspondence to Dr. Ryuta Shigefuku, shigefuku@clin.medic.mie-u.ac.jp 

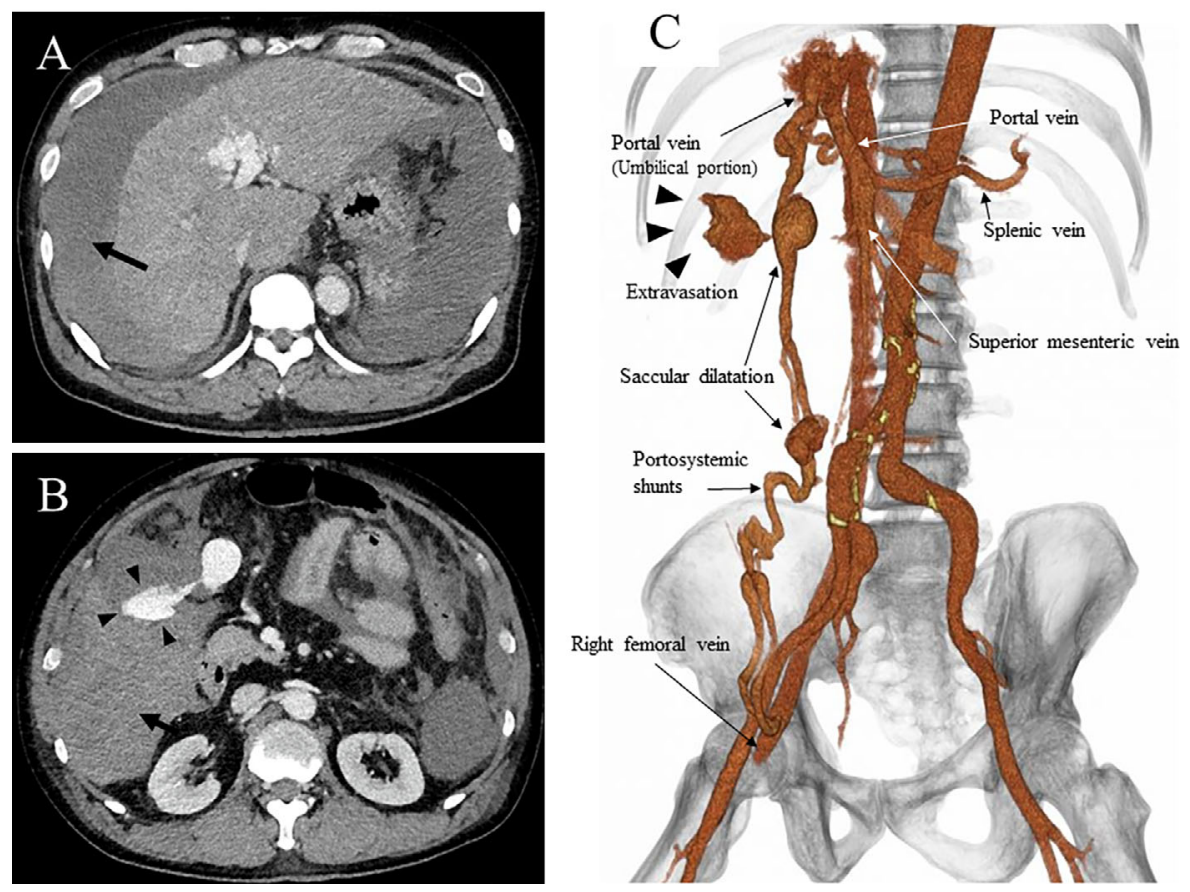

Picture 2.

\section{References}

1. Aslam N, Waters B, Riely CA. Intraperitoneal rupture of ectopic varices: two case reports and a review of literature. Am J Med Sci 335: 160-162, 2008.

2. Watanabe M, Shibuya A, Kitamura Y, et al. Intraperitoneal bleed- ing due to rupture of the left gastric vein (LGV) in a patient with liver cirrhosis: a case report. Abdom Imaging 33: 324-327, 2008.

The Internal Medicine is an Open Access journal distributed under the Creative Commons Attribution-NonCommercial-NoDerivatives 4.0 International License. To view the details of this license, please visit (https://creativecommons.org/licenses/ by-nc-nd/4.0/).

(C) 2021 The Japanese Society of Internal Medicine Intern Med 60: 959-960, 2021 